\title{
Formation indicators of strategic actions for oil and gas corporations within the framework of sustainable development concept
}

\author{
Elena Lobova ${ }^{l, *}$, Svetlana Zhukovskaya ${ }^{2}$, Alyona Taskaeva ${ }^{l}$, and Lyudmila Semina ${ }^{l}$ \\ ${ }^{1}$ Perm National Research Polytechnic University, Faculty of Humanities, Department of Economics and Industrial Production \\ Management, 29 Komsomolsky Prospekt, Perm, 614990, Russia \\ ${ }^{2}$ Perm State National Research University, Faculty of Economics, Department of Accounting, Audit and Economic Analysis 614990 , \\ Bukireva street, Perm, Russia
}

\begin{abstract}
Current trends in the global practice of forming sustainable development goals indicate that striving for innovative development is associated not only with investment activities, but also with tightening of environmental sanctions across the entire vertical of production and sales processes. Leading companies in the Russian oil and gas sector are prominent representatives of the industry and they shape their strategies in accordance with the UN Sustainable Development Goals. A study of the state of 6 companies of the oil and gas complex, which occupy stable positions in the markets of petroleum products and gas, is conducted in this paper. For the analysis, a methodology was chosen that covers the main directions in achieving the sustainable development goals: investment and innovation in technology, economic, social and environmental development. The materials of annual and consolidated reports on social, environmental and innovative development, the program of socio-economic and environmental development for 2015-2019 served as the information base for the formation of a sample of statistical indicators. The use of the benchmarking method made it possible to rank enterprises, find identity criteria, and evaluate possible strategic actions of oil and gas enterprises in achieving the integrated parameter of the Sustainable Development Index. On the basis of the obtained calculations, it is possible to form action strategies in the direction of "best practices" and adapt the worked out development programs relative to the general trend of achieving sustainable development of the oil and gas complex.
\end{abstract}

\section{Introduction}

The expert opinion of the majority of scientists involved in assessment and forecasting of innovative opportunities for implementing general schemes for industrial enterprises development [1], the problems of energy security in the framework of smart specialization strategies of developing countries [2], and the strategy of regions based on clustering the contribution of socioeconomic results of industries [3] confirms the need to adapt the list of quantitative parameters of strategic development in the direction of sustainable growth. The system paradigm of the economic growth theory puts forward the priority of the problems of effective using natural energy resources on the innovative development path. Within the concept of sustainable development alternative energy sources, such as wind energy [4], solar energy [5-6], heat energy of land [7] and other types of energy resources [8] are increasingly promoted. In turn, the key indicators of sustainable growth of energy complex enterprises will allow us to assess the contribution to the achieving the main development directions of the sustainable development concept of the country.
Despite the fact that technical and technological innovations remain a priority in the methodology of the Energy Strategy until 2050 in order to achieve the main performance indicators of the oil and gas sector [9], its sustainable development institutions, both at the interregional and international levels, should fully reflect the latest trends in formation of the goal-setting system [10]. When setting goals for achieving sustainable development at the global level for assessing indicators in countries, special attention is paid to indicators formed on the integrated approach basis [11]. Such indicators are the corresponding indices allowing one to assess the dynamics of innovative (technical and technological), social, economic and environmental aspects. With all the variety of evaluation methods, there are still no clearly defined regulatory approaches for formation of indices for economic sectors.

The main hypothesis of the study is that the aspects of the sustainable development concept should be reflected in the strategic actions of the leading companies in the oil and gas economy sector.

To prove the proposed hypothesis, the following tasks are solved in the article: 1) cross-analysis of information from open sources was carried out and the main priorities in the strategy formation for the

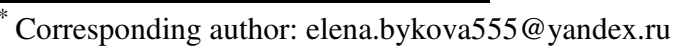


enterprise sustainable development were identified; 2) indicators for evaluating the indices of enterprise sustainable development were formed and calculated; 3) based on the benchmarking method, comparison of evaluation indicators was made and conclusions were drawn about possible directions for building strategic actions to improve the state of indicators.

\section{Methodology}

1.1 Justification of the method to select indicators for forming sustainable development indices

The need to develop indicators allowing one to parameterize the "sustainability" of advancement of civilization, countries, regions or individual market actors was noted in the "Agenda for the XXI Century", adopted at the Conference on Environment and Development in Rio de Janeiro in 1992 [12]. The relevance of this task was confirmed 20 years later at the UN Conference "Rio+20". One of the important decisions of the Conference is the need to develop sustainable development goals for the period after 2015, covering priority areas, and appropriate indicators to assess the process of achieving these goals [13]. The index system is widely represented by the leading international organizations of the United Nations, the World Bank, the OECD, the World Wildlife Union (WWF): the System of Indicators of Sustainable Development, the System of Integrated Environmental and Economic Accounting (Integrated Environmental and Economic Accounting) [14]; Human Development Index [15]; the System of environmental indicators that reflect modern technological and environmental challenges, the Ecological Footprint and the Living Planet Index) [16].

The fundamental difference between the indicators of sustainable development in comparison with their counterparts of the classical development model is consideration of environmental and social costs aimed at compensating for the cost of depleted natural resources and restoring the natural environment.

Summarizing the existing world experience in working out indicators of sustainable development, we can distinguish two approaches:

1) building an integral, aggregated indicator, on the basis of which it is possible to judge the degree of sustainability of socio-economic development. Aggregation is usually carried out on the basis of three groups of indicators: ecological-economic, ecologicalsocio-economic, or environmental;

2) building a system of indicators, each of them reflecting individual aspects of sustainable development. Most often, within the framework of the general system, the following subsystems of indicators are distinguished: economic, environmental, social, and institutional.

The choice of an approach to the development of indicators for sustainable development of oil and gas industry enterprises is advisable to form both on the basis of the comprehensive system of indicators including all the necessary assessment indicators for the 4 main areas of development, and taking into account complex aggregation in these areas, complementing the three-pronged approach of J. Elkington [17] with parameters for assessing technical and technological development.

\subsection{Approach to formation of sustainable development indicators of oil and gas enterprises}

The most prominent tools and methods for assessing sustainable development of an enterprise are:

- global 100 methodology [18];

methodology for benchmarking sustainable development based on the GDS-Index [19];

- methodology of French Association for Standards, which proposes to take into account environmental indicators in the system of sustainable development based on ISO 14001: 2015 [20];

- in recent years, the approach proposed by the Russian Union of Industrialists and Entrepreneurs (RSPP) has been developed in Russian practice [21] and implemented in the framework of competitive cases of enterprises wishing to compete for the title of Leader of Sustainable Development on the electronic platform of the Moscow Stock Exchange. This format allows you to evaluate which of the UN goals a particular enterprise implements [22].

Based on the above methodological approaches, we will determine the list of indicators that meet the requirements for forming indicators as follows:

- Assessment of technical and technological stability (k1. 1. - shelf life, k1. 2. - return on assets, k1. 3. - return on fixed assets on sales profit, k1. 4. - return on fixed assets on net profit).

- Assessment of personnel sustainability (k2. 1. production of profit from sales, production of net profit, k2. 2. - profitability of the payroll fund by profit from sales and k2.3. - profitability of the wage fund by net profit, k2. 4. - labor productivity).

- Assessment of sustainable commercial development (k3. 1. - revenue to cost ratio, k3. 2. - operating margin, k3.3. - business activity ratio, k3. 4. - return on sales by profit from sales, k3. 5. - return on sales by net profit, k3. 6. - turnover ratio of accounts receivable, k3. 7. turnover ratio of accounts payable).

- Assessment of greening (k4. 1. - degree of environmental friendliness of products, k4. 2. - degree of environmental friendliness of the enterprise, k4. 3. degree of total eco-efficiency of the enterprise (for all factors that determine eco-efficiency (water, air resources, solid waste disposal, etc., depending on the industry specifics)).

\subsection{Methodology for the formation of indicators of strategic actions to achieve a high level of sustainable development}

To choose an approach to the methodology formation, we define the term "sustainable development" 
as a single process, as a result of which there is a continuous improvement in the main financial indicators, an increase in the efficiency of investments in machinery and technology, full compliance with the requirements of environmental safety and development of social programs. The process of improving or worsening the rate of developing indicators can be implemented by calculating the indices based on the geometric mean [2324]. The methodology for developing strategic actions will also use the principles of benchmarking [25-26] and multi-criteria analysis [27-28].

The sequence of calculations will be as follows:

1) Calculation of the selected relative indicators for the four groups of sustainable development indices.

2) Determination the partial indices of the selected indicators for the period from 2015 to 2019 by the formula:

$$
I_{i j}=\frac{k_{i j}^{1}}{k_{i j}^{0}}(1)
$$

where $k_{i j}^{l}$ is the value of the selected relative indicator for the $i$-th group of indices obtained for the reporting period; $k_{i j}^{2}$ is the value of the selected relative indicator for the $i$-th group of indices obtained for the base period; $i$ is the rank of the index group from 1 to $4 ; j$ is the rank of the relative indicator in the $i$ - th group of indices.

3) Calculation of the average values of the partial indices based on the method of searching for the geometric mean $I_{i j}$ for the period from 2015 to 2019 using the formula:

$$
I S_{i j}=\sqrt[m]{\prod I_{i j}}
$$

where $m$ is the number of periods.

\section{Results and Discussion}

Cross-analysis of the data from reports on sustainable development, partial reports on financial development, implementation of environmental and social goals of the 6 largest oil and gas sector enterprises allowed us to implement paragraphs 1-3 of the proposed methodology.

The sample includes companies [29-34]. The results of the calculation of the partial indices are presented in Table 1.

Despite the fact that PJSC LUKOIL has a high rating in the aggregate index of Sustainable Development and is a leader among other companies, the results of calculations of partial and general differences indicate that this company has a leading position only in such partial indices as $\mathrm{I}_{1.2}, \mathrm{I}_{2.5}, \mathrm{I}_{3.3}, \mathrm{I}_{3.7}, \mathrm{I}_{4.1}$, and index $\mathrm{I}_{4.2}$ is the same for all companies.
Table 1. Values of partial indices of sustainable development

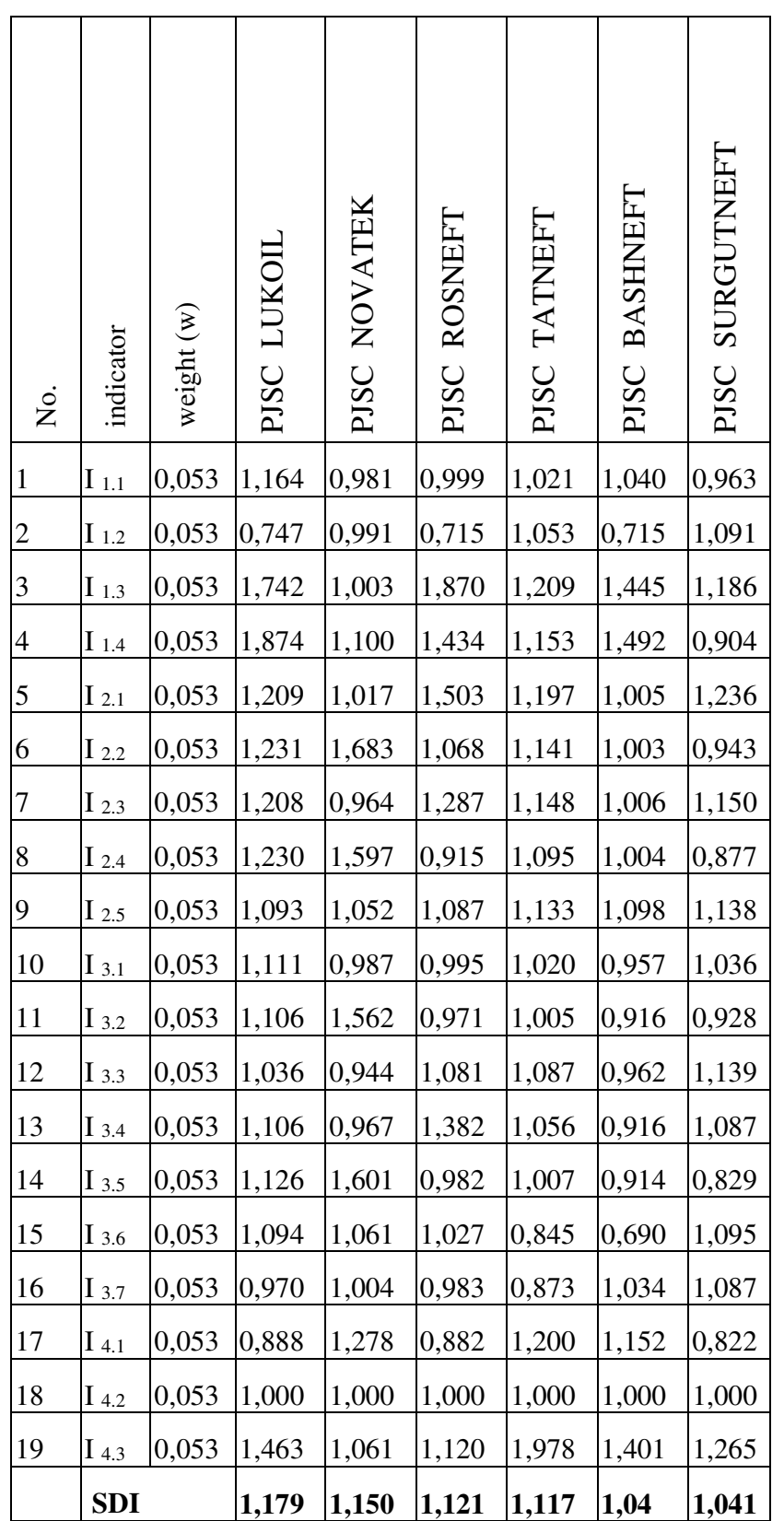

\section{Conclusion}

Implementation of the continuous growth strategy requires companies to have dynamics in the planned and implemented indicators. The data obtained indicate the positive dynamics of all the partial indices of sustainable development of the selected major representatives of the oil and gas sector. The obtained values of the Sustainable Development Indices indicate the close positions of the companies. In the process of quantifying all the indicators or bringing them to a scale from 0 to 1 , one can notice heterogeneity in the leadership positions according to particular criteria. This estimate is shown in Figure 1. 


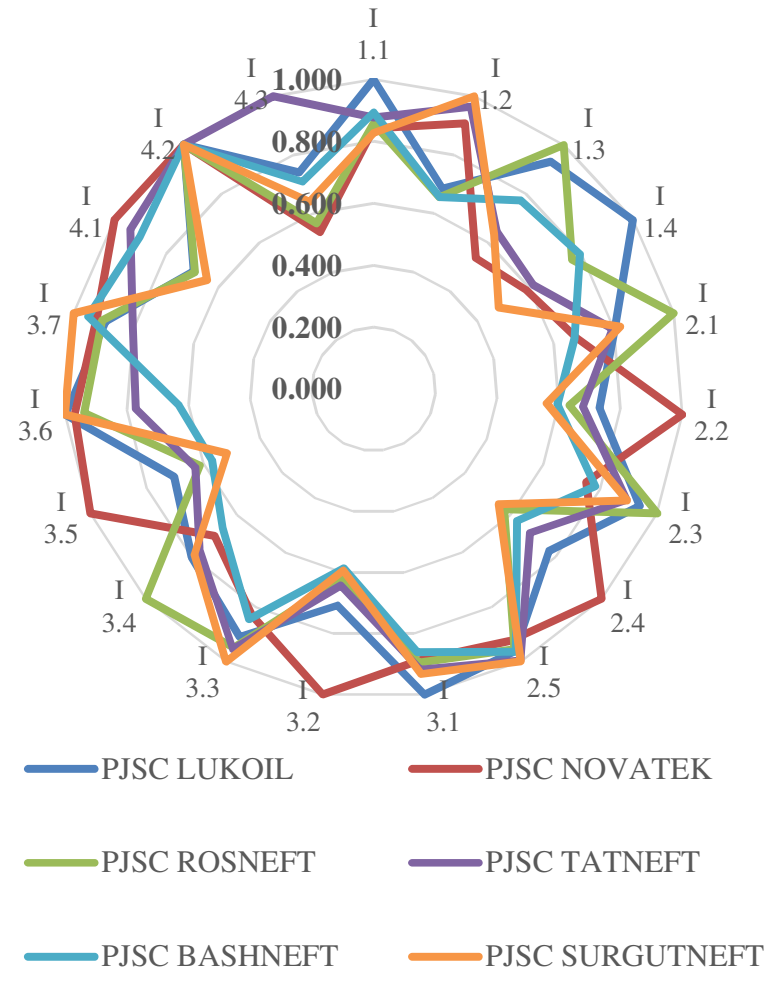

Figure 1. Comparison of quantified partial sustainable development indices.

Nevertheless, the results obtained allow us to form an approach to the gradual formation of strategic actions to further improve the indicators to the level of the best value for the industry segment. Namely, goal setting at the level of maximum parameters will allow us to form indicators of strategic actions to bring each of the companies, and the entire oil and gas sector-as a whole, to a new level of sustainable development.

\section{References}

1. I. Elokhova, L. Nazarova, Z. Mingaleva, Insights and potential sources of new entrepreneurial growth. Filodiritto Publisher, Bologna, 99-114. (2017)

2. D. Foray, X. Goenaga, JRC Scientific and Policy Reports (2013)

3. Y. Dubrovskaya, E. Kozonogova, A. Molodchik, Upravlenets-the manager, 10, 64-73 (2019)

4. V. Klimenko, E. Fedotova, Thermal Engineering, 67 (6), 331-342 (2020)

5. B.V. Ermolenko, G.V. Ermolenko, Y.A. Fetisova, L.N. Proskuryakova. Energy, 137, 1001-1012 (2017)
6. Zh. Mingaleva, N. Shpak. Thermal science, 19(2), 457-466. (2015)

7. K. Dehina, A.M. Mokhtari, B. Souyri, Geothermics, 87, 101836 (2020)

8. A.Angeloudis, S.C. Kramer, N. Hawkins, M.D. Piggott, Renewable Energy, 155, 876-888 (2020)

9. N. Vukovic, V. Pobedinsky, S. Mityagin, A. Drozhzhin, Z. Mingaleva. Sustainability (Switzerland) 11(17), 4629 (2019)

10. V. Kononov, O. Povarov, Proceedings, World Geothermal Congress (2005)

11. J. Weber, F. Gotzens, D. Witthaut. Energy Procedia, 153, 22-28 (2018)

12. Agenda 21 Retrieved from: https://undocs.org/ru/A/CONF.151/26/Rev.1\%28Vo $1.1 \% 29$

13. UN Conference "Rio $+20 "$ Retrieved from: http://www.iblfrussia.org/a-conf.216-l1_russian.pdf.pdf

14. Integrated Environmental and Economic Accounting Retrieved from: http://www.fao.org/3/bc966e/bc966e.pdf

15. Human Development Index Retrieved from: https://report.hdr.undp.org/part-2.html

16. J.A. Johnson, U. Baldos, T. Hertel, J. Liu, C. Nootenboom, S. Polasky, T. Roxburgh Global Futures: modelling the global economic impacts of environmental change to support policy-making. Technical Report, (2020) Retrieved from: https://www.wwf.org.uk/globalfutures

17. M. Kaptein, J. Wempe, Journal of Corporate Citizenship 1(2), 91-106 (2001)

18. Global 100 Retrieved from: https://www.corporateknights.com/

19. GDS-Index Retrieved from: https://www.gds.earth/wp-content/uploads/GDSIndex-2020-Methodology-1.pdf

20. ISO 14001: 2015 Retrieved from: https://www.boutique.afnor.org/norme/nf-en-iso14001/systemes-de-management-environnementalexigences-et-lignes-directrices-pour-sonutilisation/article/821532/fa176494

21. Russian Union of Industrialists and Entrepreneurs Retrieved from: https://rspp.ru/activity/social/?sphrase_id=164257

22. Moscow Exchange Competition Retrieved from: https://fs.moex.com/f/13161/etalon-2019-ar-rus.pdf

23. M. Grzebyk, M. Stec, Sustainable Development, 23, 110-123 (2015)

24. T. Alferova, E. Shilova, E. Tretiakova, European Research Studies Journal, 18(3), 115-128. (2015)

25. S.C.L. Koh, A. Gunasekaran, S.M. Saad, Benchmarking: An International Journal, 12(4), 383-400 (2005)

26. M. Ungan, Benchmarking: An International Journal, 11(5), 504-520 (2004) 
27. J.P. Brans, B. Mareschal, P. Vincke, A New Family of Outranking Methods in Multicriteria Analysis (1984)

28. J. Oberstone, Management Science - Concepts, Insights and Applications (1990)

29. official site PJSC LUKOIL Retrieved from: https://lukoil.ru/Responsibility/Sustainability

30. official site PJSC NOVATEK Retrieved from: https://www.novatek.ru/ru/development/

31. official site PJSC ROSNEFT Retrieved from: https://www.rosneft.ru/Development/

32. official site PJSC TATNEFT Retrieved from: https://www.tatneft.ru/ustoychivoerazvitie/?lang=ru

33. official site PJSC BASHNEFT Retrieved from: http://www.bashneft.ru/disclosure/

34. official site PJSC SURGUTNEFT Retrieved from: https://www.surgutneftegas.ru/responsibility/ 